\title{
The Chronic Dose Assessment of Three Critical Organs for Liver Scintigraphy with Using Cr-51
}

\author{
Ö. Maranci And A.B. Tugrul* \\ ${ }^{a}$ Istanbul Technical University, Nuclear Researches Division, Istanbul, Turkey
}

\begin{abstract}
In this study, a dosimetric study was observed by using Cr-51 gamma radioisotope on liver scintigraphy. In this context, the source organ is determined as liver and it is aimed the evaluation of measuring doses from source organ to selected three critical organs (thyroid, gonad, and brain). An antropomorphic torso phantom has been preferred in the experiments. The measurements of critical organs doses were examined for chronic effects. Moreover, the chronic effect of Cr-51 radioisotope on critical organs was determined as cumulative dose. Thermoluminescent dosimeters were used for chronic dose assessment. In the experiments, lithium fluoride (LiF) (TLD-100) detectors were used and they were provided from Turkish Atomic Energy Authority — Cekmece Nuclear Research and Training Center and calibrated in there. Within this study, the evaluation of the cumulative doses by using Cr-51 for three critical organs was observed with an original setup by using anthropomorphic torso phantom experimentally.
\end{abstract}

DOI: 10.12693/APhysPolA.132.476

PACS/topics: Cr-51, dosimetry, phantom, scintigraphy, TRIGA

\section{Introduction}

Scintigraphy is the production of two-dimensional images of the distribution of radioactivity in tissues after internal administration of a radiopharmaceutical imaging agent, the images being obtained by a scintillation camera [1]. Liver scintigraphy is widely used in nuclear medicine. Liver and spleen scintigraphy involves the intravascular administration of radiopharmaceuticals which localize in the reticuloendothelial cells or blood pool of the liver and/or spleen when given intravenously, or in the precapillary arterioles of the liver when injected through an arterial catheter into the hepatic artery. Imaging is performed with a gamma camera [2]. Liver scintigraphy plays an important role in the evaluation of liver function and structure in chronic diffuse liver diseases. Liver scintigrams provide hepatic functional and structural information based on the configuration of the liver and spleen and enable radioisotopic accumulation in the liver, spleen and bone marrow to be compared [3].

Tc- $99 \mathrm{~m}$ is widely used but Cr-51 gamma radioisotopes can be offered for this purpose [4]. Cr-51 usage is more important for patients' organ dose that has higher energy and longer half-life as compared to Tc-99m. In this study, a theoretical dosimetric study was observed by using $\mathrm{Cr}$ 51 gamma radioisotope on liver scintigraphy [5].

\section{Materials and methods}

First priority of the study was determination of which radioisotope is going to be used in the experiment. Actually, for the liver scintigraphy, Tc-99m radioisotope is generally preferred. Cr-51 gamma radioisotope is generally used for spleen scintigraphy. However, in this study

*corresponding author; e-mail: beril@itu.edu.tr
Cr-51 gamma radioisotope was decided to be used for liver scintigraphy due to its high energy and long halflife.

Chromic acid $\left(\mathrm{H}_{2} \mathrm{CrO}_{4}\right)$ compound was utilized for the experimental application. It was irradiated in central thimble of Istanbul Technical University TRIGA MARKII Research and Training Reactor at $250 \mathrm{~kW}$ for $15 \mathrm{~min}$. Therefore, Cr-51 was created by $(\mathrm{n}, \gamma)$ reaction in the reactor. Thermal neutron fluence rate can be obtained at $\approx 1.13 \times 10^{12} \mathrm{~cm}^{-2} \mathrm{~s}^{-1}$ in the central thimble of the nuclear reactor. The samples are installed in the core region to provide high level neutron absorbed dose at the irradiated specimens [6]. Total activity of the chromium compound has $0.0415 \mathrm{MBq}$ activity. The properties of Cr-51 are shown in Table I and irradiation properties of Cr-51 are shown in Table II.

Properties of Cr- 51

TABLE I

\begin{tabular}{c|c}
\hline \hline Property & Value \\
\hline symbol & Cr-51 \\
half-life & 27.7 days \\
energy & $0.32 \mathrm{MeV}$ \\
equivalent half-thickness for lead & $1.7 \mathrm{~mm}$
\end{tabular}

Irradiation properties of $\mathrm{Cr}-51$

TABLE II

\begin{tabular}{c|c|c|c|c}
\hline $\begin{array}{c}\text { Original } \\
\text { isotope }\end{array}$ & $\begin{array}{c}\text { Produced } \\
\text { radioisotope }\end{array}$ & $\begin{array}{c}\text { Irradiation } \\
\text { time }\end{array}$ & $\begin{array}{c}\text { Irradiation } \\
\text { power }\end{array}$ & $\begin{array}{c}\text { Producing } \\
\text { reaction }\end{array}$ \\
\hline Cr-50 & Cr-51 & $15 \mathrm{~min}$ & $250 \mathrm{~kW}$ & $(\mathrm{n}, \gamma)$
\end{tabular}

Anthropomorphic torso phantom [7] was used during the experimental procedure for simulation of liver scintigraphy. In this context, liver is appointed as source organ while brain, thyroid, and gonads have been appointed as the critical target organs (Fig. 1).

Thermoluminescent dosimeters (TLD) were used for cumulative dose assessment. In the experiments, lithium fluoride (LiF) (TLD-100) detectors which were provided 


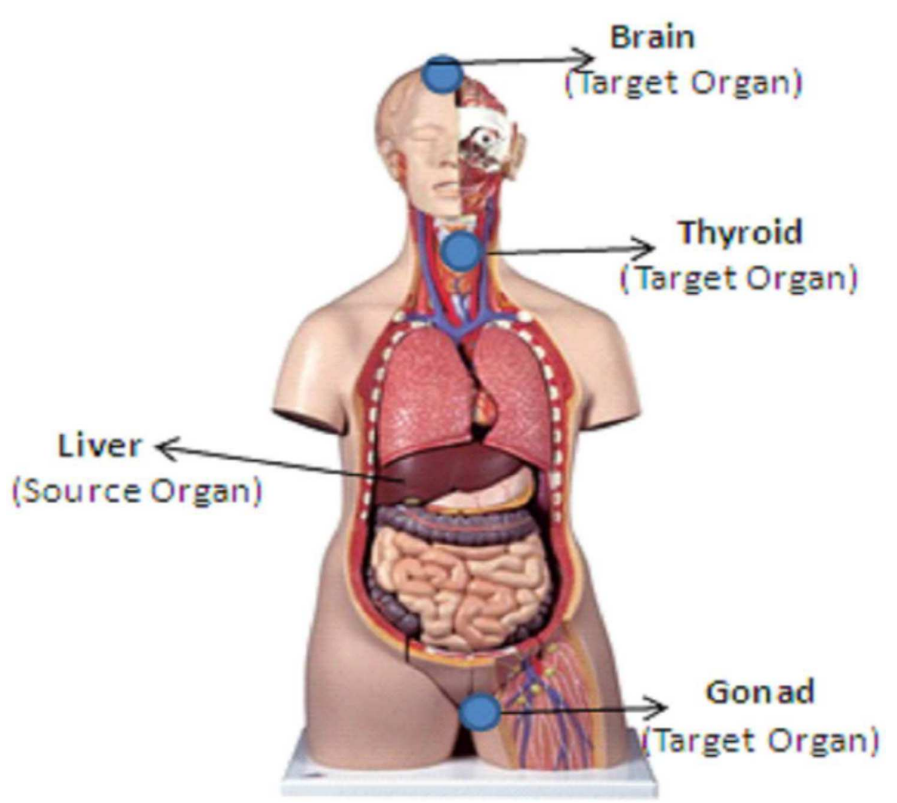

Fig. 1. Anthropomorphic torso phantom.

from Turkish Atomic Energy Authority - Çekmece Nuclear Research and Training Center were used and TLDs were calibrated in there. Thermoluminescent dosimeters have high sensitivity for tissue and tissue equivalent materials. For the calibration process of TLDs were annealed at $500^{\circ} \mathrm{C}$ for $1 \mathrm{~h}$. This annealing sets their TLD sensitivity at a standard initial value and eliminates their accumulated TL [8-10]. After that, TLDs were placed in plastic cards of each hole accommodation of the individually calibrated dosimeters. All TLDs were located at a single holder and were irradiated to the same dose with standard Cs-137 gamma source in Secondary Standard Dosimeter Laboratory (SSDL) in Turkish Atomic Energy Authority (TAEA) Cekmece Nuclear Research and Training Center. After the irradiation, all TLDs were read out on the Harshaw 2000A TLD reader. The resulting data provided a profile of relative sensitivities among TLDs in this single holder [9-13]. Actually before the dose assessment some study which shows the TLDS' sensitivities should be done and for this purpose the calibration factor for dosimeters and readers was obtained according to Cr-51. The calibration factor for dosimeters is called the element correction coefficient (ECC). ECC is used as a multiplier with the reader output to make the response of each dosimeter comparable to the average response of a designated group of dosimeters maintained as calibration dosimeters. The calibration factor for readers is known as the reader calibration factor ( $\mathrm{RCF})$. This factor converts the raw charge data from the photomultiplier tubes (in $\mathrm{nC}$ ) to dosimetric units (rems, for example) or to generic units (GU) for input to an algorithm [11].

\section{Experimental procedures}

All the experiments for determination of critical organ doses for liver scintigraphy by using Cr-51 were observed by using anthropomorphic torso phantom. Detector efficiency and radiation safety concept are important during the experimental procedures [14-16]. Chromium as powder prepared in 20 mini packages. After the irradiation, twenty packages were placed on the liver surface in anthropomorphic torso phantom as a bench-mark concept. Figure 2 shows schematically the placing of $\mathrm{Cr}-51$ packages on liver surface.

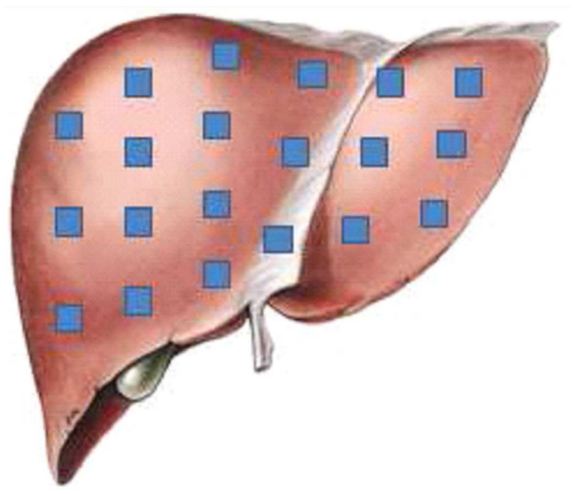

Fig. 2. Locations of Cr-51 packages on liver surface.

The experiments were done with TLD dosimeters placed on the surface of the target organs. The TLD doses were observed as the cumulative doses with collected TLD dosimeters from the anthropomorphic torso phantom after 1 day, 7 days, 15 days, and after one halflives later.

\section{Experimental results}

For the cumulative dose measurements results by using Cr-51 radioisotope for gonads, thyroid, and brain are shown for four different times (1st day, 1st week, 2nd week, 1st physical half-life) in Figs. 3-5, respectively. The comparison images of cumulative doses for the three critical organs for four different times are shown in Fig. 6 .

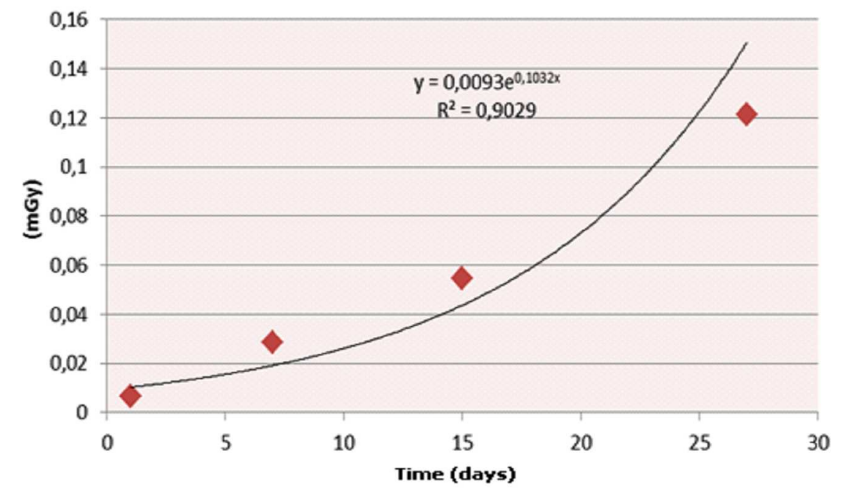

Fig. 3. Cumulative dose for gonads. 


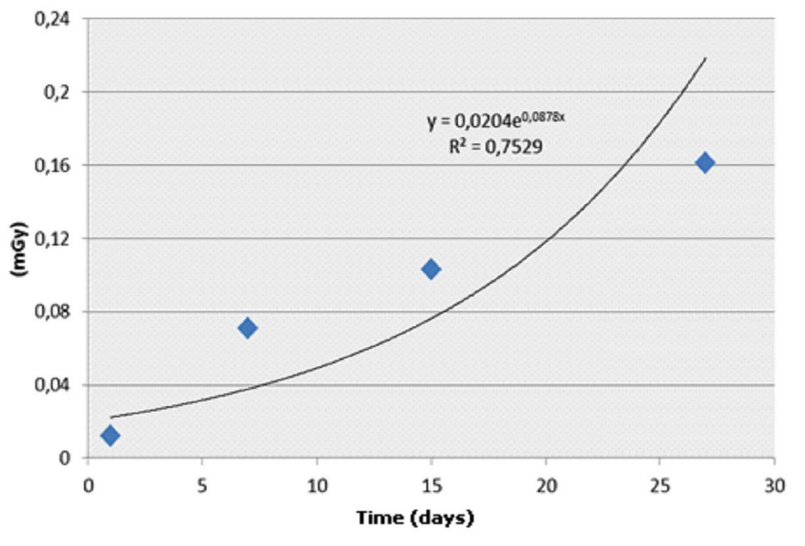

Fig. 4. Cumulative dose for thyroid.

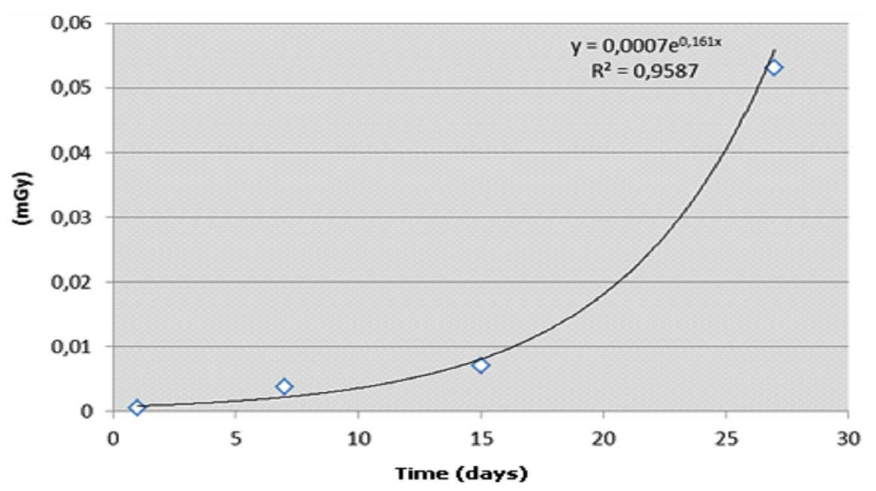

Fig. 5. Cumulative dose for brain.

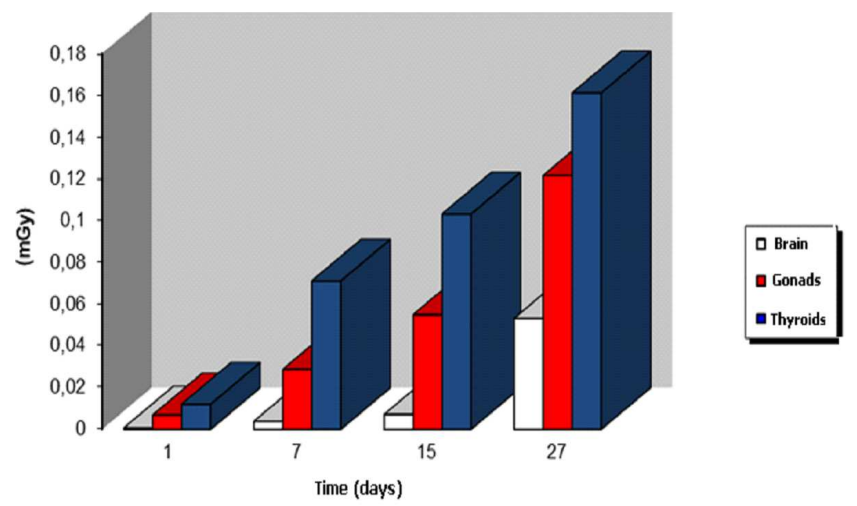

Fig. 6. Comparison of cumulative doses for three critical organs at four different times.

\section{Conclusion}

Within this study, the evaluation of the cumulative doses by using Cr-51 for three critical organs were observed with an original setup by using experimentally anthropomorphic torso phantom. Experimental results were evaluated comparatively. Results were assessed for scintigraphic application period and cumulative dose evaluation for three organs and cumulative doses were compared as a matter of fact that the radiation dose decreases via distance from the source organ as liver. Therefore, minimum dose to the maximum dose critical organs should be observed as brain, gonads, and thyroid.
Moreover, Cr-51 doses detected longer than the routine application with Tc-99m. It can be offered that Cr-51 can be used together for scintigraphic imaging technique and radiotherapy application. Therefore, if a patient has cancer and scintigraphy would be applied for control purpose, then Cr-51 can be preferable due to radiotherapic effects, too.

\section{Acknowledgments}

This study has been supported by scientific foundation of Istanbul Technical University that we are grateful of them and also we grateful to Turkish Atomic Energy Authority - Cekmece Nuclear Research and Training Center for support of the experimental procedures.

\section{References}

[1] The Free Dictionary, Medical Dictionary, scintigraphy.

[2] ACR-SNM-SPR Practice Guideline for the Performance of Liver and Spleen Scintigraphy.

[3] T. Kashiwagi, Nuclear Gastroenterology, Hyogo College of Medicine, Hyogo (Japan) 2002.

[4] Medicine Online, Liver Scintigraphy - Liver-Spleen Scan.

[5] B. Buyuk, A.B. Tugrul, Ann. Nucl. Energy 71, 46 (2014).

[6] O. Maranci, M.Sc. Thesis, Istanbul Technical University, Energy Institute, Istanbul 2016.

[7] Pacific Northwest X-ray Inc., Accessories, Phantoms Radiology, Torso, PET, 2015.

[8] J.R. Greening, in: Fundamentals of Radiation Dosimetry, Medical Physics Handbooks, Vol. 15, 2nd ed., Adam Hilger, Bristol 1981.

[9] D. Yaşar, A.B. Tuğrul, Radiat. Measur. 37, 113 (2003).

[10] D. Yaşar, A.B. Tuğrul, Appl. Radiat. Isotopes 62, 405 (2005).

[11] H. Hasabelrasoul, Estimation of uncertainty in TLD calibration.

[12] G. Yilmaz, A.B. Tugrul, M. Demir, D. Yasar, B. Demir, Acta Phys. Pol. A 130, 90 (2016).

[13] B. Buyuk, A.B. Tugrul, M. Cengiz, O. Yucel, G. Goller, F.C. Sahin, Acta Phys. Pol. A 128, B-132 (2015).

[14] İ. Akkurt, H.O. Tekin, A. Mesbahi, Acta Phys. Pol. A 128, B-332 (2015).

[15] O. Gurler, U. Akar Tarim, Acta Phys. Pol. A 130, 236 (2016).

[16] M. Cengiz, S.C. Ozer, B. Buyuk, A.B. Tugrul, O. Yucel, G. Goller, F.C. Sahin, Acta Phys. Pol. A 128, B-187 (2015). 